\title{
Inclusão de Cama de Frango em Dietas à Base de Palma Forrageira (Opuntia ficus- indica Mill) para Vacas Mestiças em Lactação. 2. Digestibilidade Aparente ${ }^{1}$
}

\author{
Maria Carla dos Santos Magalhães ${ }^{2}$, Antonia Sherlânea Chaves Véras ${ }^{3,4}$, Francisco Fernando \\ Ramos de Carvalho ${ }^{3}$, Marcelo de Andrade Ferreira ${ }^{3}$, José Nilson de Melo ${ }^{6}$, Wellington Samay \\ de Melo ${ }^{5}$, Jair Teixeira Pereira ${ }^{6}$, Mário de Andrade Lira ${ }^{3,6}$
}

\begin{abstract}
RESUMO - Os coeficientes de digestibilidade aparente de matéria seca (DAMS), de matéria orgânica (DAMO), de proteína bruta (DAPB), de extrato etéreo (DAEE), de carboidratos totais (DACHOT) e não-fibrosos (DACNF) e de fibras em detergente neutro (DAFDN) e ácido (DAFDA) foram determinados para avaliar o efeito de diferentes níveis de inclusão de cama de frango $(0 ; 10 ; 20 \mathrm{e}$ $30 \%$ ) na base da matéria seca, associados à $45 \%$ de palma forrageira, bagaço de cana de açúcar in natura, uréia e farelo de algodão, utilizandose a fibra indigestível em detergente ácido (FDAi) como indicador interno para estimar a produção de matéria seca fecal. O valor energético observado para as dietas foi comparado com o predito segundo equações propostas pelo NRC (2001). Foram utilizadas oito vacas $5 / 8$ holando-zebu com produção média de $15 \mathrm{~kg}$ de leite/dia e 420kg de peso vivo, após pico de lactação, distribuídas em dois quadrados latinos (4 x 4) simultâneos, com quatro períodos, quatro animais e quatro níveis de cama de frango na ração. Não foi observado efeito significativo do aumento do nível de cama de frango na dieta sobre DAMS, DAMO, DAEE, DACHOT e DAFDN. Entretanto, a DAPB e a DACNF diminuíram linearmente. As equações propostas pelo NRC (2001) para estimativa dos teores de nutrientes digestíveis totais das dietas superestimaram os valores observados.
\end{abstract}

Palavras-chave: bovinos de leite, farelo de algodão, nitrogênio não-protéico

\section{Inclusion of Broiler Litter in Forage Cactus Based Diets (Opuntia ficus-indica Mill) for Lactating Crossbred Cows. 2. Apparent Digestibility}

\begin{abstract}
The coeficients of apparent digestibility of dry matter (ADDM), organic matter (ADOM), crude protein (ADCP), ether extract (ADEE), total carboidrates (ADTCHO), nonfiber carboidrates (ADNFC), neutral (ADNDF) and acid detergent fiber (ADADF), were determined to evaluate the effect of diferents inclusions of broiler litter $(0,10,20$ and $30 \%$ in dry matter basis), with $45 \%$ forage cactus associaded to sugar cane bagasse, urea and cottonsead meal, using the method of indigestible acid detergent fiber as intern indicator to estimate fecal dry matter production. The dietary observed energy value were compared to the value predicted by NRC (2001). Eigth lactating 5/8 crossbred Holstein/Zebu cows with $420 \mathrm{~kg}$ of LW and production of $15 \mathrm{~kg} / \mathrm{day}$, were assigned to tratament sequences in a replicated $4 \mathrm{X} 4$ latin square with four periods, four animals and four levels of broiler in the ration. No significant effect of increasing broiler litter level was observed on ADDM, ADOM, ADEE, ADTCHO, ADNDF, ADADF. However, the ADCP and ADNFC decreased linearly. The NRC (2001) equations for estimation of total digestible nutrients overestimated the observed values.
\end{abstract}

Key Words: cottonsead meal, dairy cows, non protein nitrogen

\section{Introdução}

Segundo Ørskov (1997), os alimentos precisam ser caracterizados apropriadamente para que se confirme se seus teores de energia e proteína são utilizados eficientemente, devendo haver harmonia entre potencial animal e potencial do alimento. Nesse sentido, são utilizadas medidas de digestibilidade dos nutrientes que, segundo Van Soest (1994), classificam os alimentos quanto ao valor nutritivo, pois fornecem uma descrição qualitativa do consumo. Van Soest (1994) define digestão como processo de conversão de macromoléculas da dieta em compostos mais simples que podem ser absorvidos no trato gastrointestinal dos animais.

\footnotetext{
1 Projeto parcialmente financiado pela FACEPE e Acordo IPA/UFRPE.

${ }^{2}$ Mestre em Zootecnia - UFRPE (mariacarla0309@bol.com.br).

3 Professora do DZ - UFRPE (sherlanea@uol.com.br; ferreira@ufrpe.br; fcarva@ufrpe.br).

${ }^{4}$ Bolsista de Produtividade em Pesquisa do CNPq.

${ }^{5}$ Aluno de graduação Zootecnia - UFRPE - Bolsista PIBIC/CNPq/FACEPE.

${ }^{6}$ Pesquisador do IPA - PE.
} 
A palma é uma das mais importantes forrageiras utilizadas na pecuária leiteira do Estado de Pernambuco e apresenta digestibilidade superior à da maioria das forrageiras adaptadas ao semi-árido (Santos et al., 1997). Santos et al. (1990) relataram digestibilidade in vitro da matéria seca (MS) de 77,37\% para a cultivar miúda, enquanto para a gigante e redonda os valores foram de, respectivamente, 75,12 e 74,11\%.

Pode-se destacar, para a palma forrageira, altos teores de carboidratos solúveis (Santos et al., 1992), e deficiência de proteína bruta (PB), com apenas 4,45 a $6,82 \%$ na MS, valor inferior às necessidades dos microrganismos do rúmen (Van Soest, 1994). Além disso, possui fibra e alta umidade. As pesquisas realizadas até o momento indicam a necessidade de se avaliar a palma forrageira associada a outros alimentos que possam corrigir deficiências nutricionais e distúrbios metabólicos, ou maximizar sua utilização.

A fibra é fundamental para manter as condições ótimas do rúmen, pois altera as proporções de ácidos graxos voláteis, estimula a mastigação e mantém o pH em níveis adequados para a atividade microbiana (Mertens, 1992). Pode ser definida como a fração indigestível, ou lentamente digestível, dos alimentos que ocupa espaço no trato gastro intestinal dos animais, limitando a ingestão de alimentos (Mertens, 1997).

Para ruminantes, a cama de frango, é uma fonte importante de NNP na forma de ácido úrico (Conn \& Stumpf, 1980) e sua associação com a palma forrageira também consiste em importante fonte de fibra. Apesar de a amônia ser a principal fonte de $\mathrm{N}$ para o crescimento bacteriano, peptídeos e aminoácidos também são necessários, sobretudo em dietas de baixa qualidade (alta fibra e baixa proteína), em que mais de $40 \%$ do $\mathrm{N}$ bacteriano não provêm da amônia. Estes são também precursores de cadeias de ácidos graxos e funcionam como fatores de crescimento para diversas bactérias, especialmente as celulolíticas (Russell \& Hespell,1981). Assim, torna-se necessária, na composição da dieta, a inclusão de uma fonte de proteína verdadeira, como exemplo, o farelo de algodão.

Os requerimentos para mantença e produção de leite são expressos como energia líquida para lactação $\left(E L_{L}\right)$, em virtude de as eficiências de utilização da energia metabolizável para mantença e produção serem similares.

A edição do NRC (2001) difere substancialmente das versões anteriores quanto à forma de se obter $\mathrm{e}$ expressar os valores energéticos dos alimentos. Segundo este Conselho, a determinação dos valores de energia no NRC (1989) incorria em alguns problemas, destacando-se que a maior parte dos valores de nutrientes digestíveis totais (NDT) de alimentos tabelados era baseada em experimentos conduzidos há muito tempo e era apropriada somente quando a composição de nutrientes do alimento era a mesma que a utilizada no ensaio de digestibilidade. Para alguns alimentos, o NDT não podia ser mensurado diretamente, porque o alimento não representava a maior parte da dieta, e o cálculo do NDT utilizando o método de diferença não tinha boa acurácia; poucos valores de energia metabolizável (EM) e EL para alimentos individuais eram disponíveis; as equações utilizadas para converter NDT em EM e EL eram derivadas de dietas completas e assumia-se que todas as vacas consumiam três vezes a mantença.

Assim, no NRC (2001), os valores de NDT são calculados até uma vez a mantença $\left(\mathrm{NDT}_{1 \mathrm{X}}\right)$, a partir dos dados de composição da dieta, utilizandose equações para estimativa das digestibilidades verdadeiras de carboidratos não-fibrosos, da proteína dos volumosos e concentrados; de ácidos graxos e de fibra em detergente neutro (FDN), diferenciadas para cada fonte protéica e lipídica; deduzindo-se do somatório das frações digestíveis, o fator de correção igual a sete, relativo ao NDT metabólico fecal, visto que são computadas as digestibilidades verdadeiras.

Da mesma forma, para obter a energia digestível em nível de mantença $\left(\mathrm{ED}_{1 \mathrm{X}}\right)$, o NRC (2001) preconiza equações diferenciadas para alimentos que contenham fontes de proteína animal, para dietas suplementadas com gordura, com e sem glicerol e demais alimentos, e calcula a ED como o produto da concentração das frações digestíveis do alimento, utilizadas para o cálculo do $\mathrm{NDT}_{1 \mathrm{X}}$, pelos respectivos valores de calor de combustão, menos a ED metabólica fecal, de $0,3 \mathrm{Mcal} / \mathrm{kg}$.

Além disto, assume redução da digestibilidade com o aumento do consumo de alimentos, o que acontece em maior grau à medida que a dieta é mais digestível, concluindo que, ao se calcular a ED em níveis de consumo acima da mantença ED de produção (EDp), é necessário utilizar equação de ajuste (\% de desconto). Porém, em dietas com valores de $\mathrm{NDT}_{1 \mathrm{X}}$ iguais ou menores que $60 \%$, esta diminuição na digestibilidade é negligenciável.

Para a energia metabolizável de produção $\left(\mathrm{EM}_{\mathrm{P}}\right)$, a partir da qual, segundo o NRC (2001) é calculada a energia líquida de lactação para produção $\left(\mathrm{EL}_{\mathrm{Lp}}\right)$, a equação é a mesma proposta no NRC (1989); exceto 
para dietas com alto percentual de gordura. Houve, portanto, avanço em relação ao NRC (1989) que calculava a $\mathrm{EL}_{\mathrm{L}}$ diretamente a partir do NDT, o que resultava em eficiências semelhantes em converter ED para $\mathrm{EL}_{\mathrm{L}}$, para todos os alimentos.

Conduziu-se este trabalho objetivando avaliar o efeito das associações de palma forrageira $(45 \%$ da MS), cama de frango $(0 ; 10 ; 20$ e $30 \%)$, uréia, bagaço de cana e farelo de algodão sobre a digestibilidade aparente dos nutrientes em dietas fornecidas a vacas mestiças leiteiras e comparar os valores energéticos observados e estimados para as dietas experimentais, segundo equações propostas pelo NRC (2001).

\section{Material e Métodos}

O experimento foi conduzido na Estação Experimental da Empresa Pernambucana de Pesquisa Agropecuária (IPA), em Caruaru, durante 84 dias, divididos em quatro períodos de 21 dias (14 de adaptação às dietas experimentais e sete para coletas). Antes da implantação do ensaio, os animais permaneceram cerca de 15 dias nas instalações, para adaptação ao manejo.

Foram utilizadas oito vacas 5/8 Holandês-Gir, após pico de lactação, com peso vivo médio de $418 \mathrm{~kg}$ e produção de leite média diária de $15 \mathrm{~kg}$. As vacas foram alojadas em baias individuais e distribuídas, aleatoriamente, nos tratamentos que continham, em relação à matéria seca (MS), 45\% de palma forrageira
(Opuntia ficus indica Mill), cultivar gigante, associados a farelo de algodão, bagaço de cana in natura e níveis crescentes de cama de frango $(0 ; 10$; 20 e 30\%), tendo como substrato casca de arroz. Foram adicionados à dieta uréia, visando manter níveis satisfatórios de $\mathrm{PB}$, mistura mineral, para atender os requerimentos minerais, e monofosfato de amônio (MAP), como fonte de fósforo (Tabelas $1 \mathrm{e} 2$ ). As rações foram formuladas de acordo com as recomendações do NRC (1989), para atender às exigências de produção de $15 \mathrm{~kg}$ de leite/vaca/dia, com 4\% de gordura. Nas Tabelas 3 e 4, são apresentadas, respectivamente, as composições bromatológicas das misturas e volumosos e das dietas experimentais. A alimentação foi fornecida na forma de ração completa, em três refeições diárias, uma pela manhã, às $8 \mathrm{~h}$, e duas à tarde, às 14 e $17 \mathrm{~h}$. Os animais tiveram acesso à água três vezes ao dia.

Para estimativa do consumo, foram efetuadas pesagens, amostragens e registros diários da quantidade dos alimentos fornecidos e das sobras, que foram ajustadas para, no máximo, $10 \%$ do fornecido, objetivando proporcionar o consumo voluntário, porém, garantindo a manutenção das proporções dos ingredientes das rações nos diferentes tratamentos experimentais. Para determinar as digestibilidades aparentes da MS, matéria orgânica (MO) proteína bruta $(\mathrm{PB})$, fibra em detergente neutro (FDN), carboidratos totais (CHOT) e não-fibrosos (CNF), foram efetuadas coletas de fezes dos animais,

Tabela 1 - Composição percentual dos ingredientes das dietas

Table 1 - Percentage of the ingredients in the diets

\begin{tabular}{|c|c|c|c|c|}
\hline \multirow[t]{2}{*}{$\begin{array}{l}\text { Ingredientes ( } \% \text { da MS) } \\
\text { Ingredients (\% of DM) }\end{array}$} & \multicolumn{4}{|c|}{$\begin{array}{l}\text { Níveis de cama de frango ( } \% \mathrm{MS}) \\
\text { Levels of broiler litter (\% of DM) }\end{array}$} \\
\hline & $0 \%$ & $10 \%$ & $20 \%$ & $30 \%$ \\
\hline $\begin{array}{l}\text { Palma } \\
\text { Forage cactus }\end{array}$ & 44,36 & 44,45 & 45,14 & 45,28 \\
\hline $\begin{array}{l}\text { Bagaço de cana-de-açúcar } \\
\text { Sugar cane bagasse }\end{array}$ & 35,86 & 28,93 & 21,39 & 13,40 \\
\hline $\begin{array}{l}\text { Farelo de algodão } \\
\text { Cottonseed meal }\end{array}$ & 17,12 & 14,96 & 12,00 & 9,65 \\
\hline $\begin{array}{l}\text { Cama de frango } \\
\text { Broiler litter }\end{array}$ & 0,00 & 9,51 & 19,94 & 30,69 \\
\hline $\begin{array}{l}\text { Uréia } \\
\text { Urea }\end{array}$ & 1,38 & 1,13 & 0,83 & 0,37 \\
\hline $\begin{array}{l}\text { Sal mineral } \\
\text { Mineral salt }\end{array}$ & 0,53 & 0,57 & 0,59 & 0,61 \\
\hline $\begin{array}{l}\text { MAP } \\
A P M\end{array}$ & 0,75 & 0,46 & 0,12 & 0,00 \\
\hline
\end{tabular}

R. Bras. Zootec., v.33, n.6, p.1909-1919, 2004 (Supl. 1) 
diretamente no reto, antes do fornecimento da alimentação diária, nos segundo e penúltimo dias de cada período de coleta.

As amostras de fezes foram armazenadas a $-15^{\circ} \mathrm{C}$ e, em seguida, da mesma forma que os alimentos e sobras, pré-secas, processadas em moinhos com peneira de malha de $1 \mathrm{~mm}$ e agrupadas de forma proporcional, para constituírem amostras compostas, por período, por animal e por tratamento. Após, foram homogeneizadas, para retirada de uma alíquota representativa para análises posteriores.

A estimativa da produção fecal foi efetuada utilizando-se a fibra em detergente ácido indigestível (FDAi) como indicador. As amostras de fezes, de alimentos e de sobras foram incubadas in situ, em sacos tipo ANKON, por um período de 144 horas no rúmen de um bovino adulto, segundo metodologia adaptada à descrita por Berchielli et al. (2000), diferindo apenas quanto à incubação.

A quantidade da amostra incubada foi de $1,0 \mathrm{~g}$ para alimentos e sobras, em razão da alta degradabilidade dos concentrados e da palma forrageira, e $0,5 \mathrm{~g}$ para fezes. O material remanescente da incubação foi submetido à extração com detergente ácido e o resíduo considerado FDAi. Para cálculo da matéria seca fecal (MSF), utilizou-se a fórmula: MSF $(\mathrm{kg})=($ Indicador consumido $(\mathrm{kg}) /$ Concentração do indicador nas fezes).

O coeficiente de digestibilidade aparente (CDA) foi calculado segundo Silva \& Leão (1979): CDA = $\{[($ Consumo de nutrientes $(\mathrm{kg})$ - Nutrientes excretado nas fezes $(\mathrm{kg})] /$ Consumo de nutrientes $(\mathrm{kg}) * 100\}$.

Tabela 2 - Composição percentual das misturas de ingredientes secos

Table 2 - Percentage of the ingredients in the dry mixtures

\begin{tabular}{|c|c|c|c|c|}
\hline \multirow[t]{2}{*}{$\begin{array}{l}\text { Ingredientes (\% MS) } \\
\text { Ingredients }(\% D M)\end{array}$} & \multicolumn{4}{|c|}{$\begin{array}{l}\text { Misturas } \\
\text { Mixtures }\end{array}$} \\
\hline & M1 & M2 & M3 & M4 \\
\hline Farelo de algodão & 86,55 & 56,17 & 35,84 & 23,36 \\
\hline $\begin{array}{l}\text { Cottonseed meal } \\
\text { Cama de frango } \\
\text { Broiler litter }\end{array}$ & 0,00 & 35,73 & 59,55 & 74,28 \\
\hline $\begin{array}{l}\text { Broiler litter } \\
\text { Uréia } \\
\text { Urea }\end{array}$ & 6,99 & 4,25 & 2,48 & 0,89 \\
\hline $\begin{array}{l}\text { Sal mineral } \\
\text { Mineral salt }\end{array}$ & 2,69 & 2,13 & 1,76 & 1,47 \\
\hline $\begin{array}{l}\text { MAP } \\
A P M\end{array}$ & 3,77 & 1,72 & 0,37 & 0,00 \\
\hline
\end{tabular}

R. Bras. Zootec., v.33, n.6, p.1909-1919, 2004 (Supl. 1)
As análises laboratoriais de MS e de nutrientes foram obtidas determinando os teores de MS, MO e PB, conforme segundo Silva (1990); de FDN e FDA, de acordo com Van Soest (1991); de CHOT e consumo de nutrientes digestíveis totais (CNDT), segundo Snifen et al. (1992), enquanto os carboidratos não-fibrosos (CNF) foram determinados conforme Mertens (1997):

$$
\begin{gathered}
\mathrm{CHOT}=100-(\mathrm{PB}+\mathrm{EE}+\mathrm{Cinzas}) \\
\mathrm{CNDT}=(\mathrm{PB} \text { ing. }-\mathrm{PB} \text { fecal })+2,25(\mathrm{EE} \text { ing. }- \\
\mathrm{EE} \text { fecal })+(\mathrm{CHT} \text { ing. }-\mathrm{CHT} \text { fecal }) \\
\mathrm{CNF}=100-(\text { FDN }+\mathrm{PB}+\mathrm{EE}+\text { Cinzas })
\end{gathered}
$$

Apenas referentes aos ingredientes da ração foram determinados os teores de lignina, segundo Silva (1990); nitrogênio não-protéico (NNP), segundo Licitra et al. (1996); nitrogênio insolúvel em detergente neutro (NIDN), nitrogênio insolúvel em detergente ácido (NIDA) e FDN corrigida para cinzas e proteína (FDNcp), segundo Snifen et al. (1992).

$\mathrm{Na}$ estimativa do teor de NDT para mantença $\left(\mathrm{NDT}_{1 \mathrm{X}}\right)$ e de energia digestível para mantença $\left(\mathrm{ED}_{1 \mathrm{X}}\right)$ das dietas e dos alimentos utilizados, segundo o NRC (2001), para determinar a digestibilidade verdadeira dos CNF (DVCNF), com fator de ajuste para processamento (FAP) igual a 1; da proteína bruta de forragens (DVPBf) e de concentrados (DVPBc); dos ácidos graxos (DVAG) e da FDN (DVFDN), foram utilizadas as seguintes equações:

$$
\begin{aligned}
& \text { DVCNF }=0,98[100-((\text { NDF-PIDN })+\text { PB }+ \text { EE } \\
& + \text { CINZAS })] * \text { FAP } \\
& \mathrm{DVPBf}=\mathrm{PB}^{*} \exp [-1,2 *(\mathrm{PIDA} / \mathrm{PB})] \\
& \text { DVPBc }=[1-(0,4 *(\mathrm{PIDA} / \mathrm{PB}))]^{*} \mathrm{~PB} \\
& \mathrm{DVAG}=\mathrm{EE}-1 \text {. Se } \mathrm{EE}<1 \text {, então } \mathrm{AG}=0 \\
& \text { DVFDN }=0,75 *[(\text { FDN-PIDN })- \\
& \text { LIGNINA]*[1-(LIGNINA/(FDN-PIDN } \left.\left.)^{0,667}\right)\right] \\
& \begin{array}{c}
\mathrm{NDT}_{1 \mathrm{X}}(\%)=\mathrm{DVCNF}+\mathrm{DVPBc}+\mathrm{DVPBf}+ \\
\left(\mathrm{DVEE}^{*} 2,25\right)+\mathrm{DVFDN}-7
\end{array} \\
& \mathrm{ED}_{1 \mathrm{X}}(\mathrm{Mcal} / \mathrm{kg})=\left(\mathrm{DVCNF}^{* 100)} * 4,2+\right. \\
& (\mathrm{DVPBc} * 100) * 5,6+(\mathrm{DVPBf} * 100) * 5,6 \\
& +\left(\text { DVAG }^{*} 100\right) 9,4+\left(\text { DVFDN }^{*} 100\right) * 4,2-0,3
\end{aligned}
$$

Para obtenção da ED a partir dos valores de NDT 
obtidos segundo Sniffen et al. (1992), foi utilizada a equação, de acordo com o NRC(1989):

$$
\mathrm{ED}(\mathrm{Mcal} / \mathrm{kg})=0,04409 * \mathrm{NDT} \%
$$

Para o cálculo das energias metabolizáveis para produção $\left(\mathrm{EM}_{\mathrm{P}}\right)$ e líquidas para lactação e produção $\left(\mathrm{EL}_{\mathrm{Lp}}\right)$, foram adotadas as equações:

$\operatorname{EM}_{\mathrm{P}}(\mathrm{Mcal} / \mathrm{kg})=1,01 * \mathrm{ED}(\mathrm{Mcal} / \mathrm{kg})-0,45$
$\mathrm{EL}_{\mathrm{Lp}}(\mathrm{Mcal} / \mathrm{kg})=[0,703 * \mathrm{EMp}(\mathrm{Mcal} / \mathrm{kg})]-0,19$

O delineamento experimental foi em quadrado latino ( $4 \times 4)$, sendo quatro animais, quatro períodos e quatro níveis de inclusão de cama de frango nas rações. Foram utilizados dois quadrados simultâneosum com vacas de $4^{\mathrm{a}}$ lactação e outro com de $8^{\mathrm{a}}$ lactação. Os dados foram submetidos à análise de

Tabela 3 - Teores de matéria seca (MS), proteína bruta (PB), extrato etéreo (EE), carboidratos totais (CHOT) e não-fibrosos (CNF), fibras em detergente neutro (FDN) e em detergente ácido (FDA), FDN corrigida para cinza e proteína (FDNcp), matéria mineral (MM), matéria orgânica (MO), proteínas insolúveis em detergente neutro (PIDN) e em detergente ácido (PIDA), nitrogênio não-protéico (NNP) e lignina (LIG) das misturas e dos volumosos das dietas experimentais

Table 3 - Contents of dry matter (DM), crude protein $(C P)$, ether extract (EE), total carbohydrates (TC), nonfiber carbohydrates (NFC), neutral detergent fiber (NDF), acid detergent fiber (ADF), NDF correct to ash and protein, mineral matter (MM), organic matter (OM), neutral detergent insoluble protein (NDIP), acid detergent insoluble protein (ADIP), nonprotein nitrogen (NPN) and lignin (LIG) of the dry mixtures and forages of the experimental diets

\begin{tabular}{|c|c|c|c|c|c|c|}
\hline \multirow[t]{2}{*}{$\begin{array}{l}\text { Nutrientes } \\
\text { Nutrients }\end{array}$} & \multicolumn{4}{|c|}{$\begin{array}{l}\text { Misturas } \\
\text { Mixtures }\end{array}$} & \multicolumn{2}{|c|}{$\begin{array}{c}\text { Volumosos } \\
\text { Forages }\end{array}$} \\
\hline & M1 & M2 & M3 & M4 & $\begin{array}{l}\text { Bagaço de } \\
\text { cana-de- } \\
\text { açúcar } \\
\text { Sugar cane } \\
\text { bagasse }\end{array}$ & $\begin{array}{l}\text { Palma } \\
\text { Cactus }\end{array}$ \\
\hline $\begin{array}{l}\text { MS \% } \\
D M\end{array}$ & 80,19 & 78,99 & 77,23 & 76,80 & 77,95 & 8,72 \\
\hline $\begin{array}{l}\mathrm{PB}^{1} \\
C P\end{array}$ & 46,33 & 38,03 & 32,08 & 28,60 & 2,32 & 5,14 \\
\hline $\begin{array}{l}\mathrm{EE}^{1} \\
E E\end{array}$ & 1,19 & 1,22 & 1,78 & 1,64 & 0,52 & 0,85 \\
\hline $\begin{array}{l}\mathrm{CHOT}^{1} \\
T C\end{array}$ & 44,26 & 48,89 & 50,90 & 52,82 & 92,62 & 86,02 \\
\hline $\begin{array}{l}\mathrm{CNF}^{1} \\
N F C\end{array}$ & 1,87 & 3,66 & 5,55 & 5,24 & 8,23 & 50,93 \\
\hline $\begin{array}{l}\mathrm{FDN}^{1} \\
N D F\end{array}$ & 42,39 & 45,23 & 45,35 & 47,58 & 84,39 & 35,09 \\
\hline $\begin{array}{l}\mathrm{FDA}^{1} \\
A D F\end{array}$ & 28,82 & 28,40 & 26,57 & 27,56 & 65,51 & 23,88 \\
\hline $\begin{array}{l}\text { FDNcp }^{1} \\
\text { NDFap }\end{array}$ & 37,38 & 38,77 & 38,75 & 41,08 & 80,91 & 32,49 \\
\hline $\begin{array}{l}\mathrm{MM}^{1} \\
M M\end{array}$ & 8,23 & 11,87 & 15,24 & 16,95 & 4,54 & 7,99 \\
\hline $\begin{array}{l}\mathrm{MO}^{1} \\
O M\end{array}$ & 91,64 & 88,01 & 85,48 & 84,08 & 95,67 & 92,02 \\
\hline $\begin{array}{l}\mathrm{PIDN}^{1} \\
N D I P\end{array}$ & 1,95 & 3,49 & 4,34 & 4,71 & 1,19 & 1,46 \\
\hline $\begin{array}{l}\text { PIDA }^{1} \\
A D I P\end{array}$ & 1,90 & 1,86 & 1,88 & 1,93 & 1,72 & 1,17 \\
\hline $\begin{array}{l}\mathrm{NNP}^{1} \\
N P N\end{array}$ & 20,70 & 17,19 & 11,94 & 10,88 & 0,73 & 2,45 \\
\hline $\begin{array}{l}\mathrm{LIG}^{1} \\
L I G\end{array}$ & 11,19 & 9,63 & 7,23 & 7,98 & 14,20 & 7,07 \\
\hline
\end{tabular}

R. Bras. Zootec., v.33, n.6, p.1909-1919, 2004 (Supl. 1) 
variância e de regressão por intermédio do programa SAEG (Sistemas de Análises Estatísticas e Genéticas) (UFV, 1997).

Os critérios utilizados para a escolha do modelo foram a significância dos coeficientes de regressão observada por meio do teste $\mathrm{F}$, em níveis de 1 e $5 \%$ de probabilidade, o coeficiente de determinação $\left(\mathrm{r}^{2} / \mathrm{R}^{2}\right)$, obtido pela relação entre a soma dos quadrados da regressão e a soma de quadrados dos tratamentos e, segundo Sampaio (1998), o fenômeno biológico.

\section{Resultados e Discussão}

$\mathrm{Na}$ Tabela 5, são apresentados os coeficientes de digestibilidade aparente dos nutrientes, expressos em percentagem e os teores de nutrientes digestíveis totais (NDT). Não foram observadas diferenças significativas em relação às digestibilidades da matéria seca (MS), fibras em detergente neutro (FDN) e ácido (FDA), matéria orgânica (MO) e carboidratos totais (CHOT). Porém, à medida que aumentou a inclusão de cama de frango (CF) na dieta, houve queda da digestibilidade da proteína bruta $(\mathrm{PB})$ e dos carboidratos não-fibrosos (CNF) e aumento do coeficiente de digestibilidade aparente do extrato etéreo (EE).

Apesar de a CF ser fonte de NNP na forma de ácido úrico (Conn \& Stumpf, 1980), houve adição de uréia em todas as dietas experimentais (Tabela 2). Esta adição foi reduzida à medida que se incluiu CF, o que resultou em níveis de NNP similares entre as dietas. Além disso, a palma forrageira apresentou $47,65 \%$ da PB na forma de NNP e apesar de possuir baixo teor de $\mathrm{PB}$, em decorrência da quantidade proporcional que foi utilizada, a palma contribuiu com $1,10 \%$, em média, da matéria seca das dietas na forma de NNP.

Considerando a pequena variação entre as dietas em relação à quantidade de NNP (Tabela 4), não é possível explicar a diminuição da digestibilidade da $\mathrm{PB}$, em razão da menor quantidade de proteína verdadeira nas dietas com maior inclusão de CF. No entanto, é possível que os níveis de NNP tenham comprometido a digestibilidade de todas as dietas. Mello (2002), avaliando o aumento dos níveis de NNP (2,31 a $8,02 \%$ da MS) em dietas com, em média, $36,38 \%$ de palma, não verificou efeito sobre a DAPB, porém houve redução linear nas DAMS e DAMO.

Com exceção da DACNF, todos os coeficientes de digestibilidade obtidos foram inferiores aos descritos na literatura consultada em dietas constituídas por palma forrageira. Andrade et al. (2002), avaliando dietas contendo níveis crescentes de palma $(0 ; 12 ; 24 ;$ e $36 \%$ na MS), obteve $73,01 \%$ de DAMS; 74,47\% de DAMO; 74,54\% de DAPB; $43,85 \%$ de DAFDN e $53,80 \%$ de DAFDA, para o

Tabela 4 - Teores de matéria seca (MS), proteína bruta $(\mathrm{PB})$, extrato etéreo (EE), carboidratos totais (CHOT) e não-fibrosos (CNF), fibras em detergente neutro (FDN) e em detergente ácido (FDA), matérias mineral (MM) e orgânica (MO), proteínas insolúveis em detergente neutro (PIDN) e detergente ácido (PIDA), nitrogênio não-protéico (NNP), lignina (LIG) e nutrientes digestíveis totais (NDT) das dietas experimentais

Table 4 - Contents of dry matter (DM), crude protein (CP), ether extract (EE), total carbohydrates (TC), nonfiber-carbohydrates (NFC), neutral detergent fiber (NDF), acid detergent fiber (ADF), mineral matter $(M M)$, organic matter (OM), neutral detergent insoluble protein (NDIP), acid detergent insoluble protein (ADIP), nonprotein nitrogen (NPN), lignin (LIG) and total digestible nutrients (TDN) of experimental diets

\begin{tabular}{|c|c|c|c|c|}
\hline \multirow[t]{2}{*}{$\begin{array}{l}\text { Nutrientes } \\
\text { Nutrients }\end{array}$} & \multicolumn{4}{|c|}{$\begin{array}{l}\text { Níveis de cama de frango ( } \% \mathrm{MS} \text { ) } \\
\text { Levels of broiler litter (\% of DM) }\end{array}$} \\
\hline & $0 \%$ & $10 \%$ & $20 \%$ & $30 \%$ \\
\hline MS (\%) & 17,22 & 17,20 & 16,97 & 16,91 \\
\hline $\begin{array}{l}D M \\
\mathrm{~PB}^{1}\end{array}$ & 12,23 & 13,03 & 13,54 & 14,42 \\
\hline $\begin{array}{l}C P \\
\mathrm{EE}^{1} \\
E E\end{array}$ & 0,802 & 0,861 & 1,098 & 1,138 \\
\hline $\begin{array}{l}\mathrm{CHOT}^{1} \\
T C\end{array}$ & 80,17 & 78,07 & 75,54 & 73,20 \\
\hline $\begin{array}{l}\mathrm{CNF}^{1} \\
N F C\end{array}$ & 25,87 & 25,96 & 26,44 & 26,34 \\
\hline $\begin{array}{l}\mathrm{FDN}^{1} \\
N D F\end{array}$ & 54,31 & 52,10 & 49,10 & 46,88 \\
\hline $\begin{array}{l}\text { FDA }^{1} \\
A D F\end{array}$ & 39,79 & 37,11 & 33,65 & 30,96 \\
\hline $\begin{array}{l}\mathrm{MM}^{1} \\
M M\end{array}$ & 6,79 & 8,00 & 9,80 & 11,20 \\
\hline $\begin{array}{l}\mathrm{MO}^{1} \\
O M\end{array}$ & 93,58 & 92,33 & 90,95 & 89,57 \\
\hline $\begin{array}{l}\mathrm{PIDN}^{1} \\
N D I P\end{array}$ & 1,46 & 1,92 & 2,37 & 2,77 \\
\hline $\begin{array}{l}\text { PIDA }^{1} \\
A D I P\end{array}$ & 1,51 & 1,51 & 1,53 & 1,55 \\
\hline $\begin{array}{l}\mathrm{NNP}^{1} \\
N P N\end{array}$ & 5,45 & 5,82 & 5,22 & 4,98 \\
\hline $\begin{array}{l}\mathrm{LIG}^{1} \\
L I G\end{array}$ & 10,46 & 9,83 & 8,66 & 8,95 \\
\hline $\begin{array}{l}\operatorname{NDT}(\%)^{*} \\
T D N\end{array}$ & 52,34 & 49,76 & 49,32 & 48,12 \\
\hline
\end{tabular}


tratamento contendo $36 \%$ de palma, verificando que o efeito de sua inclusão na dieta apresentou comportamento quadrático, similar à adição de concentrados.

Mello (2002) obteve 67,09; 68,61; 76,45; 50,32 e $56,94 \%$, respectivamente, para DAMS; DAMO; DAPB; DAFDN e DAFDA, em dieta contendo $40,88 \%$ de palma e $8,02 \%$ de nitrogênio não-protéico (NNP). Diante destes valores, pode-se inferir que os baixos coeficientes de DAMS obtidos neste trabalho decorreram, provavelmente, dos reduzidos coeficientes de digestibilidade aparente da FDN e da FDA, presentes na composição das dietas, e/ou dos níveis elevados de bagaço de cana in natura, ou de $\mathrm{CF}$, cujo substrato foi casca de arroz (Tabela 1).
Além disso, provavelmente contribuíram para a redução dos coeficientes de digestibilidade os altos consumos de MS, como relatado por Magalhães (2002), que foram estimulados por fatores psicogênicos e pela baixa densidade energética da dieta $(48,12$ a $52,34 \%$ de NDT) e representaram valores médios de 3,94\% do PV, ou seja, 21,60\% maior que o preconizado pelo NRC (2001). Apesar de o NRC (2001) considerar negligenciável a diminuição da digestibilidade com o aumento de ingestão, quando as dietas possuem $60 \%$ ou menos de NDT, o maior consumo de MS representou excessivo consumo de FDN que, em percentagem do PV, foi de 1,97\%, em média; valor $61,47 \%$ maior que a capacidade de consumo de FDN/dia preconizada por Mertens (1992).

Tabela 5 - Médias, coeficientes de variação (CV) e de determinação $\left(R^{2} / r^{2}\right)$ e equações de regressão para os coeficientes de digestibilidade aparente de matéria seca (DAMS), de proteína bruta (DAPB), de extrato etéreo (DAEE), de fibra em detergente neutro (DAFDN), de fibra em detergente ácido (DAFDA), de matéria orgânica (DAMO), de carboidratos totais (DACHOT) e não-fibrosos (DACNF) e teores de nutrientes digestíveis totais (NDT), em função dos níveis de cama de frango (CF) das rações experimentais

Table 5 - Means, coefficients of variation (CV) and determination $\left(R^{2} / r^{2}\right)$ and regression equations for coefficients of apparent digestibility of dry matter (ADDM), crude protein $(A D C P)$, ether extract (ADEE)) neutral detergent fibre (ADNDF) and acid detergent fibee (ADADF), organic matter (ADOM), total carbohydrates (ADTC), nonfiber carbohydrates (ADNFC) and total digestible nutrients (TDN), according to the broiler litter levels

\begin{tabular}{|c|c|c|c|c|c|c|c|}
\hline \multirow{2}{*}{$\begin{array}{l}\text { Variáveis } \\
\text { Variables } \\
(\%)\end{array}$} & \multicolumn{4}{|c|}{$\begin{array}{l}\text { Níveis de cama de frango } \\
\text { Levels of broiler litter }\end{array}$} & \multirow{2}{*}{$\begin{array}{l}\mathrm{CV} \\
\mathrm{CV} \\
(\%)\end{array}$} & \multirow[t]{2}{*}{$\begin{array}{l}\mathrm{R}^{2} \\
(\%)\end{array}$} & \multirow[t]{2}{*}{$\begin{array}{l}\text { Equações } \\
\text { Equations }\end{array}$} \\
\hline & $0 \%$ & $10 \%$ & $20 \%$ & $30 \%$ & & & \\
\hline $\begin{array}{l}\text { DAMS } \\
A D D M\end{array}$ & 53,54 & 51,47 & 51,93 & 50,49 & 8,55 & NS & $=51,97$ \\
\hline $\begin{array}{l}\mathrm{DAPB} \\
A D C P\end{array}$ & 58,87 & 52,99 & 53,37 & 47,96 & 13,10 & 88 & $=8,9303-0,359336 \mathrm{CF}^{* *}$ \\
\hline $\begin{array}{l}\text { DAEE } \\
A D E E\end{array}$ & 20,17 & 19,39 & 37,55 & 36,89 & 21,80 & 67 & $=22,2422+0,54384 \mathrm{CF}^{*}$ \\
\hline $\begin{array}{l}\text { DAFDN } \\
A D N D F\end{array}$ & 37,14 & 37,54 & 35,96 & 37,44 & 13,66 & NS & $=37,00$ \\
\hline $\begin{array}{l}\text { DAFDA } \\
A D A D F\end{array}$ & 34,98 & 33,70 & 31,90 & 31,05 & 17,99 & NS & $=32,95$ \\
\hline $\begin{array}{l}\text { DAMO } \\
A D O M\end{array}$ & 56,02 & 54,17 & 54,86 & 53,85 & 7,56 & NS & $=54,80$ \\
\hline $\begin{array}{l}\text { DACHOT } \\
\text { ADTC }\end{array}$ & 55,52 & 54,15 & 54,28 & 54,70 & 7,92 & NS & $=54,75$ \\
\hline $\begin{array}{l}\text { DACNF } \\
A D N F C\end{array}$ & 91,25 & 86,60 & 86,98 & 84,61 & 4,77 & 81 & $=90,3013-0,191215 \mathrm{CF}^{*}$ \\
\hline $\begin{array}{l}\text { NDT } \\
T D N\end{array}$ & 52,34 & 49,76 & 49,32 & 48,12 & - & - & - \\
\hline
\end{tabular}

** Significativos a $1 \%$ (significant at $1 \%$ of probability).

* Significativos a $5 \%$ (significant at $5 \%$ of probability).

NS Não-significativo (not significant).

R. Bras. Zootec., v.33, n.6, p.1909-1919, 2004 (Supl. 1) 
Os altos teores de FDN, quando associados a altos níveis de consumo, promovem diminuição da digestibilidade (Mertens, 1997).

Segundo Russell \& Hespell (1981), peptídeos e aminoácidos são necessários, sobretudo em dietas de baixa qualidade (alta fibra e baixa proteína), em que mais de $40 \%$ do nitrogênio bacteriano não provêm da amônia, por serem precursores de cadeias de ácidos graxos e funcionarem como fatores de crescimento para diversas bactérias, particularmente as celulolíticas.

O NRC (2001) recomenda, em dietas com, no máximo $36 \%$ de CNF, percentuais mínimos de $21 \%$ de FDA e $33 \%$ de FDN, com $15 \%$ de FDN proveniente de volumosos. Como as dietas apresentaram, em média, $26,15 \%$ de CNF; $35,38 \%$ de FDA e $50,60 \%$ de FDN (Tabela 4) e considerando que os percentuais de 81,38; 76,78; 69,01; e 58,01\% da FDN são provenientes da forragem, respectivamente, para as dietas com $0 ; 10 ; 20$ e 30\% de CF (Tabela 7), obtidos por Magalhães (2002), as dietas utilizadas se enquadram na categoria de alto conteúdo de fibra.

Na Tabela 6, são apresentados os valores estimados de proteína bruta microbiana (PBM), de requerimentos de proteína degradada no rúmen (PDR) e de consumo de NNP para as dietas experimentais. Verifica-se que os consumos de NNP forneceram, em média, 70,18\% dos requerimentos de PDR. Considerando que a PDR é composta por NNP e proteína verdadeira degradável no rúmen, provavelmente houve excesso de PDR em todas as dietas experimentais e, principalmente, na dieta com $10 \%$ de CF.
Segundo Pereira et al. (2000), a CF, além de apresentar menor quantidade da fração B2 (fonte de aminoácidos e peptídeos tanto no rúmen como no intestino delgado), em relação ao farelo de algodão, possui proporção significativa de seu nitrogênio na forma de proteína de lenta degradação, fração B3 $(23,57 \%)$, que tende a escapar do rúmen e fornecer aminoácidos no intestino delgado, e fração C elevada $(10,11 \%)$, indigerível. Estes fatores podem contribuir para esclarecer a queda na digestibilidade da $\mathrm{PB}$ à medida que aumentou a inclusão de CF nas dietas, considerando ainda que houve concomitante redução dos percentuais de farelo de algodão.

Em relação às frações de carboidratos, segundo Pereira et al. (2000), o farelo de algodão apresenta superioridade da fração A + B1 (46,36\%), podendo implicar em melhor adequação energética ruminal e resultar em melhor crescimento microbiano.

Em razão de as dietas serem constituídas por alto percentual de NNP proveniente da uréia, da CF e da palma, e haver semelhança em relação ao percentual de palma forrageira nas dietas (Tabela 1), aquelas que possuíam uma segunda boa fonte de carboidratos solúveis, provavelmente promoveram melhor adequação energética ruminal, ocasionando maior coeficiente de digestibilidade dos carboidratos não-fibrosos.

Em razão das características próprias da digestão de gorduras em ruminantes, a maior recuperação nas fezes (observada nas dietas com 0 e $10 \%$ de inclusão de $\mathrm{CF}$, que implicou em menor coeficiente de digestibilidade), foi, provavelmente, decorrente da melhor adequação

Tabela 6 - Valores estimados de produção de proteína bruta bacteriana (PBM), requerimentos de proteína degradável no rúmem (PDR) e consumo de nitrogênio não-protéico (NNP) para as dietas experimentais

Table 6 - Estimated values of microbial crude protein (MCP), requeriments for ruminal degradable protein (RDP) and nonprotein nitrogen (NPN) of the experimentals diets

\begin{tabular}{lcccc}
\hline $\begin{array}{l}\text { Variáveis (g) } \\
\text { Variables }\end{array}$ & \multicolumn{4}{c}{$\begin{array}{c}\text { Níveis de cama de frango } \\
\text { Levels of broiler litter }\end{array}$} \\
\cline { 2 - 5 } & $0 \%$ & $10 \%$ & $20 \%$ & $30 \%$ \\
\hline PBM & 1067,3 & 1136,2 & 1069,9 & 989,3 \\
$\begin{array}{l}\text { ReP } \\
\text { RDPerimento de PDR }\end{array}$ & 1259,41 & 1340,72 & 1262,47 & 1167,36 \\
$\begin{array}{l}\text { Consumo de NNP } \\
N P N \text { intake }\end{array}$ & 854,56 & 1021,98 & 872,20 & 788,82 \\
$\begin{array}{l}\text { NNP (\% da PDR) } \\
N P N(\% \text { of } R D P)\end{array}$ & 67,85 & 76,23 & 69,09 & 67,57 \\
\hline
\end{tabular}

R. Bras. Zootec., v.33, n.6, p.1909-1919, 2004 (Supl. 1) 
ruminal destas dietas e, conseqüentemente, do maior desenvolvimento microbiano.

De modo geral, uma afirmação precisa sobre as digestibilidades aparentes avaliadas necessitaria do conhecimento da síntese microbiana e das características do ambiente ruminal.

Houve, para as dietas experimentais, correlação de $97 \%$ entre os teores de NDT observados e a DAMO (Figura 1). Como a DAMO está relacionada ao teor energético da dieta, esta informação pode contribuir na formulação de dietas pois, na prática, a determinação da DAMO é mais econômica que a do NDT (Branco et al. 2001).

$\mathrm{Na}$ Figura 2, encontra-se a relação entre os valores de NDT estimados segundo o NRC (2001) e os observados, determinados a partir do consumo de NDT, segundo Sniffen et al. (1992), mantendo correlação de 0,82 . Contudo, as concentrações energéticas estimadas foram superiores às observadas, exceto para o tratamento com $0 \%$ de CF

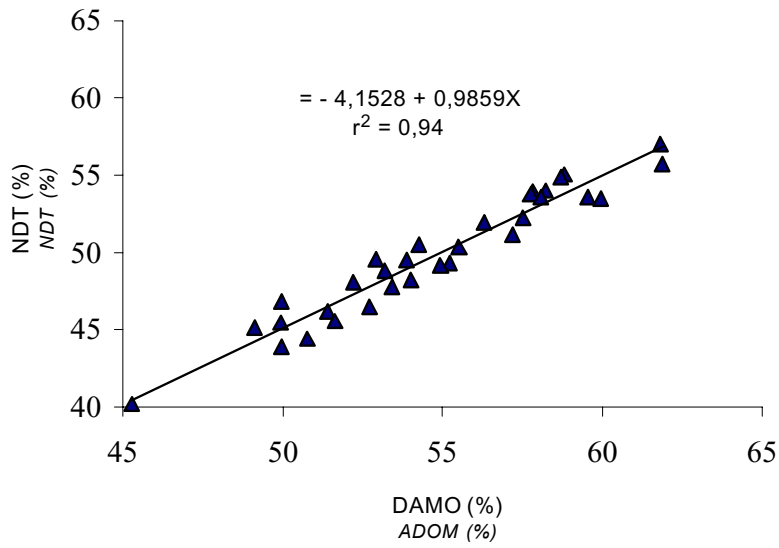

Figura 1 - Relação entre os teores de nutrientes digestíveis totais (NDT) e os coeficientes de digestibilidade aparente da matéria orgânica (DAMO) das dietas.

Figure 1 - Relation between levels of total digestibles nutrients (TDN) of diets and coefficients of aparent digestibility of organic matter (ADOM).

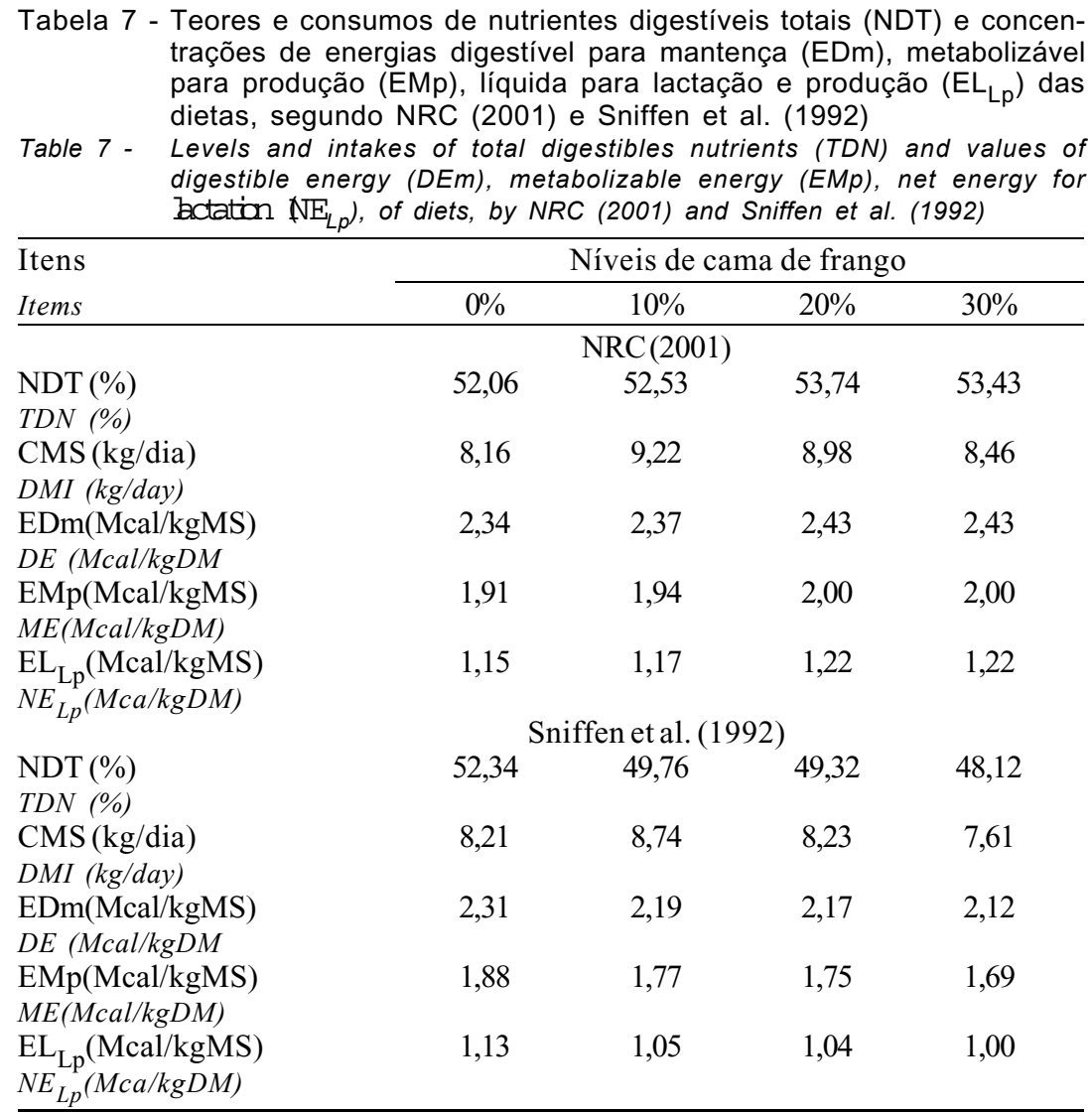

R. Bras. Zootec., v.33, n.6, p.1909-1919, 2004 (Supl. 1) 
(Tabela 7). Este comportamento era esperado, porque, segundo advertência do NRC (2001), os valores de energia para alimentos e dietas são baseados apenas nas características químicas, de modo que estas características limitam a disponibilidade de energia. Porém, a composição da dieta total e o consumo de MS têm marcantes efeitos na digestibilidade. Além disso, dietas que não promovem ótima fermentação ruminal podem ter os valores de energia superestimados e efeitos associativos positivos não são considerados.

Na Tabela 7, são apresentados os teores e consumos de NDT estimados e observados, além das concentrações de energias digestível para mantença, metabolizável de produção, líquida de lactação e produção. As concentrações de ED calculadas a partir dos teores de NDT, como sugere o NRC (1989), foram menores que as estimadas segundo proposta do NRC (2001), com reflexo nas concentrações energéticas das dietas.

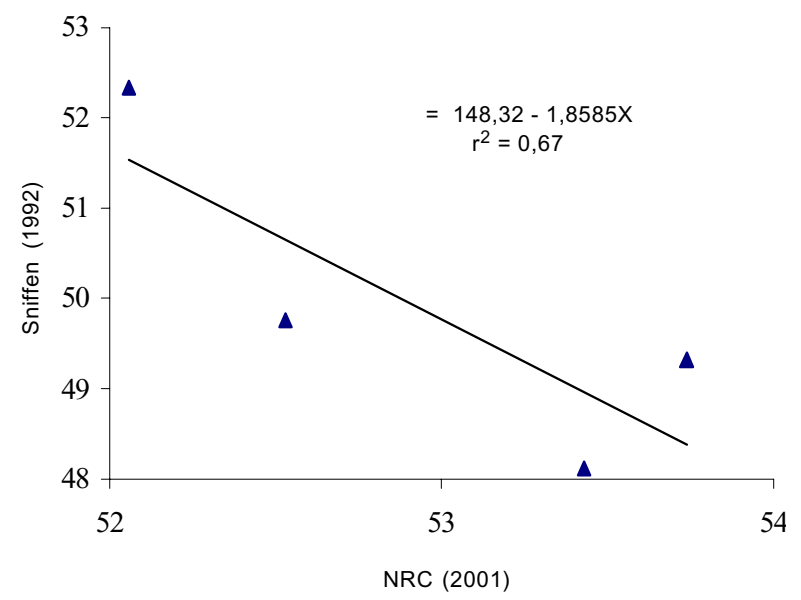

Figura 2 - Relação entre os teores de nutrientes digestíveis totais (NDT) das dietas utilizando o consumo de NDT, segundo Sniffen et al. (1992), e os estimados, segundo o NRC (2001).

Figure 2 - Relation between coefficients of total digestibles nutrients (TDN) of diets to make use the intake of TDN and the estimated by NRC (2001).
Segundo Hall (2001), o cálculo dos CNF sem correção da FDN para proteína é mais utilizado, porém a equação proposta por Sniffen et al (1992) é preferida porque evita que se subtraia a proteína insolúvel em detergente neutro (PIDN) duas vezes (como parte da PB e da FDN). Na obtenção dos teores de NDT, segundo o NRC (2001), deve-se observar a recomendação de corrigir a FDN, sem a qual os valores de NDT serão subestimados.

Os teores de NDT estimados segundo o NRC (2001), para palma forrageira e bagaço de cana, foram de 61,13 e 39,02\%, com concentração de ED de 2,67 e 1,65 Mcal $/ \mathrm{kg}$. Em relação às misturas secas dos tratamentos com $0 ; 10 ; 20$ e $30 \%$ de $\mathrm{CF}$, foram estimados, respectivamente, os teores de 55,36; 52,$81 ; 53,15$ e $49,65 \%$ de NDT; e as concentrações de ED de 2,96; 2,73; 2,65 e 2,47 Mcal $/ \mathrm{kg}$.

Diante destes resultados, pode-se inferir a riqueza da palma forrageira em energia, confirmando o relato de Mello (2002), que estimou o NDT da palma em $63,73 \%$. Vale ressaltar que o teor de EE da palma obtido no presente trabalho foi inferior a $1 \%$ (Tabela 3), diferente dos 2,06 relatados pelo mesmo autor. Assim, a estimativa da digestibilidade verdadeira do EE, segundo o NRC (2001), seria igual a zero. Além disso, a percentagem de FDN determinada nesse estudo foi superior à encontrada por Mello (2002).

$\mathrm{Na}$ Tabela 8, são apresentados os consumos preditos de MS e de energia e as exigências diárias, segundo o NRC (1989) e o NRC (2001), para vacas com $420 \mathrm{~kg}$ de peso vivo (PV), escore 3,5; na oitava semana de lactação, produzindo $15 \mathrm{~kg}$ de leite com $4 \%$ de gordura, peso à maturidade de $500 \mathrm{~kg}$, não gestantes, na terceira lactação.

Apesar do alto consumo de MS, apenas a dieta com $10 \%$ de $\mathrm{CF}$ atendeu às exigências diárias de $\mathrm{EL}_{\mathrm{Lp}}$ para produção de 15 litros/dia.

\section{Conclusões}

A inclusão de cama de frango em dietas contendo palma forrageira e alta concentração de FDN acarreta redução nos coeficientes de digestibilidade da proteína bruta e dos carboidratos não-fibrosos.

As equações propostas pelo NRC (2001) para estimativa dos teores de nutrientes digestíveis totais das dietas superestimaram os valores observados. 
Tabela 8 - Consumos preditos de matéria seca (CMS), nutrientes digestíveis totais (CNDT), energia digestível em nível de mantença (EDm), energia metabolizável para produção (EMp), energia líquida para lactação $\left(E L_{L p}\right)$, teores de NDT e requerimento de energia líquida para lactação $\left(\mathrm{EL}_{\mathrm{Lp}}\right)$, segundo o NRC (1989) e NRC (2001)

Table 8 - Predicted intakes of dry matter (DMI), total digestibles nutrients (TDNI), digestible energy at maintainance (DEm), metabolizable energy for production (EMp), net energy for lactation $\left(N E_{L}\right)$, levels of TDN and requirements of $N E_{L}$, by NRC (1989) and NRC (2001)

\begin{tabular}{|c|c|c|}
\hline $\begin{array}{l}\text { Itens } \\
\text { Items }\end{array}$ & NRC(1989) & NRC (2001) \\
\hline CMS (kg/dia) & 12,19 & 13,61 \\
\hline $\begin{array}{l}\text { DMI (kg/day) } \\
\operatorname{NDT}(\%) \\
T D N(\%)\end{array}$ & 66,73 & 59,93 \\
\hline $\begin{array}{l}\text { CNDT }(\mathrm{kg} / \text { dia }) \\
\text { TDNI }((\mathrm{kg} / \text { day })\end{array}$ & 8,13 & 8,15 \\
\hline $\begin{array}{l}\mathrm{EDm}(\mathrm{Mcal} / \mathrm{kgMS}) \\
D E(\text { Mcal } / \mathrm{kg} D M)\end{array}$ & 2,94 & 2,64 \\
\hline $\begin{array}{l}\mathrm{EMp}(\mathrm{Mcal} / \mathrm{kgMS}) \mathrm{ME} \\
(\mathrm{Mcal} / \mathrm{kgDM})\end{array}$ & 2,52 & 2,22 \\
\hline $\begin{array}{l}\mathrm{EL}_{\mathrm{Lp}}(\mathrm{Mcal} / \mathrm{kgMS}) \\
N E_{I n}(\mathrm{Mca} / \mathrm{kg} D M)\end{array}$ & 1,51 & 1,37 \\
\hline $\begin{array}{l}\mathrm{EL}_{\mathrm{Lp}}^{L p}(\mathrm{Mcal} / \mathrm{dia}) \\
N E_{L p}(\text { Mcal/day })\end{array}$ & 18,46 & 18,64 \\
\hline
\end{tabular}

\section{Literatura Citada}

ANDRADE, D.K.B.; FERREIRA, M.A.; VÉRAS, A.S.C. et al. Digestibilidade e absorção aparentes em vacas da raça holandesa alimentadas com palma forrageira (Opuntia ficusindica Mill) em substituição à silagem de sorgo (Sorghum bicolor (L.) Moench). Revista Brasileira de Zootecnia, v.32, n.5, p.2088-2097, 2002.

BERCHIELLI, T.T.; ANDRADE, P.; FURLAN, C.L. Avaliação de indicadores internos em ensaio de digestibilidade. Revista Brasileira de Zootecnia, v.29, n.3, p.830-833, 2000.

CONN, E.E.; STUMPF, P.K. Introdução a bioquímica. 4.ed. São Paulo: Edgar Blucher, 1980. 525p.

HALL, M.B. Recentes avanços em carboidratos não fibrosos na nutrição de vacas leiteiras. In: SIMPÓSIO INTERNACIONAL DE BOVINOCUlTURA DE LEITE, 2001. Lavras. Anais.. Lavras: Universidade Federal de Lavras, 2001. v.2. p.198.

MAGALHÃES, M.C.S. Cama de frango associada à palma forrageira (Opuntia ficus-indica Mill) na alimentação de vacas mestiças em lactação. Recife: Universidade Federal Rural de Pernambuco, 2002. 73p. Dissertação (Mestrado em Zootecnia) - Universidade Federal Rural de Pernambuco, 2002.

MELLO, A.A.S. Substituição parcial do farelo de soja por uréia e palma forrageira (Opuntia ficus-indica Mill cv. Gigante) em dietas para vacas em lactação. Recife: Universidade Federal Rural de Pernambuco, 2002. 52p. Dissertação (Mestrado em Nutrição Animal) - Universidade Federal Rural de Pernambuco, 2002.
MERTENS, D.R. Análise da fibra e sua utilização na avaliação e formulação de rações. In: SIMPÓSIO INTERNACIONAL DE RUMINANTES, REUNIÃO ANUAL DA SOCIEDADE BRASILEIRA DE ZOOTECNIA, 29., 1992, Lavras. Anais... Lavras: Sociedade Brasileira de Zootecnia, 1992. p.188-219.

MERTENS, D.R. Creating a system for meeting the fiber requirements of dairy cows. Journal of Dairy Science, v.80, p. 1463-1481, 1997

NATIONAL RESEARCH COUNCIL - NRC. Nutrient requirements of the dairy cattle. 6 . ed. Washington, D. C: National Academy Press. 1989. 158p.

NATIONAL RESEARCH COUNCIL - NRC. Nutrient requirements of the dairy cattle. 6.ed. Washington, D. C: National Academy Press. 2001. 381p.

ORSKOV, E.R. Avaliação da proteína e energia em ruminantes. In: SIMPÓSIO INTERNACIONAL DE DIGESTIBILIDADE EM RUMINANTES, 1997, Lavras. Lavras: Universidade Federal de Lavras, 1997. p.289-302.

PEREIRA, E.S.; QUEIROZ, A.C.; PAULINO, M.F. et al. Determinação das frações protéicas e de carboidratos e taxas de degradação in vitro da cana de açúcar, da cama de frango e do farelo de algodão. Revista Brasileira de Zootecnia, v.29, n.6, p.1887-1893, 2000.

RUSSELL, J.B.; HESPELL, R.B. Microbial rumen fermentation. Journal of Dairy Science, v.64, p.1153-1169, 1981.

SAMPAIO, I.B.M. Estatística aplicada à experimentação animal. Belo Horizonte: Fundação de Ensino e Pesquisa em Medicina Veterinária, 1998. 221p.

SANTOS, D.C.; FARIAS, I.; LIRA, M.A.; TAVARES FILHO, J.J. et al. A palma forrageira (Opuntia ficus-indica Mill e Napalea cochenillifera Salm-Dick) em Pernambuco: cultivo e utilização. Recife: Empresa Pernambucana de Pesquisa Agropecuária, 1997. 23p. (Documentos, 25).

SANTOS, M.V.F.; LIRA, M.A.; FARIAS, I. et al. Estudo comparativo das cultivares de palma forrageira "Gigante" "Redonda" (Opuntia ficus-indica Mill) e "Miúda" (Napalea cochenillifera Salm-Dick) na produção de leite. Revista Brasileira de Zootecnia, v.19, n.6, p.504-511, 1990.

SANTOS, M.V.F.; LIRA, M.A.; FARIAS, I. et al. Efeito do período de armazenamento pós-colheita sobre o teor de matéria seca e composição química das palmas forrageiras. Pesquisa Agropecuária Brasileira, v.27, n.6, p.777-783, 1992.

SILVA, D.J. Análise de alimentos (métodos químicos e biológicos). Viçosa, MG: Universidade Federal de Viçosa, 1990. $165 \mathrm{p}$.

SILVA, J.F.C.; LEÃO, M.I. Fundamentos na nutrição animal. Piracicaba: Livroceres, 1979.

SNIFFEN, C.J.; O'CONNOR, J.D.; Van SOEST, P.J. A net carbohydrate and protein system for evaluating cattle diets. II. Carbohydrate and protein availability. Jornal of Animal Science, v.70, p.3562-3577, 1992.

UNIVERSIDADE FEDERAL DE VIÇOSA-UFV. SAEG Sistemas de Análises Estatísticas e Genéticas. Versão 7.1. Viçosa, MG: 1997. 150 p. (Manual do usuário).

Van SOEST, P.J. Nutritional ecology of the ruminant. 2.ed. Cornell University Press, 1994. 47p.

R. Bras. Zootec., v.33, n.6, p.1909-1919, 2004 (Supl. 1)

Recebido em: 20/08/03

Aceito em: 15/04/04 